\title{
A new precast wall connection subjected to monotonic loading
}

\begin{abstract}
Final construction project cost is significantly determined by construction rate. The Industrialized Building System (IBS) was promoted to enhance the importance of prefabrication technology rather than conventional methods in construction. Ensuring the stability of a building constructed by using IBS is a challenging issue. Accordingly, the connections in a prefabricated building have a basic, natural, and essential role in providing the best continuity among the members of the building. Deficiencies of conventional precast connections were observed when precast buildings experience a large induced load, such as earthquakes and other disasters. Thus, researchers aim to determine the behavior of precast concrete structure with a specific type of connection. To clarify this problem, this study investigates the capacity behavior of precast concrete panel connections for industrial buildings with a new type of precast wall-to-wall connection (i.e., U-shaped steel channel connection). This capacity behavior is compared with the capacity behavior of precast concrete panel connections for industrial buildings that used a common approach (i.e., loop connection), which is subjected to monotonic loading as in-plane and out-of-plane loading by developing a finite element model. The principal stress distribution, deformation of concrete panels and welded wire mesh (BRC) reinforcements, plastic strain trend in the concrete panels and connections, and crack propagations are investigated for the aforementioned connection. Pushover analysis revealed that loop connections have significant defects in terms of strength for in-plane and out-of-plane loads at three translational degrees of freedom compared with the U-shaped steel channel connection.
\end{abstract}

Keyword: Industrial building systems; Precast concrete structures; Wall connection; Monotonic loading; Pushover analysis; Finite element analysis 
